Correction

\title{
Correction: Sato, M., et al. Total Optimization of Energy Networks in a Smart City by Multi-Population Global-Best Modified Brain Storm Optimization with Migration, Algorithms 2019, 12, 15
}

\author{
Mayuko Sato ${ }^{1}$, Yoshikazu Fukuyama ${ }^{1, *(D)}$, Tatsuya Iizaka ${ }^{2}$ and Tetsuro Matsui ${ }^{2}$ \\ 1 Graduate School of Advanced Mathematical Sciences, Meiji University, Tokyo 164-8525, Japan; \\ cs173017@meiji.ac.jp \\ 2 Fuji electric CO., Ltd., Tokyo 141-0032, Japan; iizaka-tatsuya@fujielectric.com (T.I.); \\ matsui-tetsuro@fujielectric.com (T.M.) \\ * Correspondence: yfukuyam@meiji.ac.jp; Tel.: +81-3-5343-8293
}

Received: 6 June 2019; Accepted: 17 June 2019; Published: 21 June 2019

The authors wish to make the following corrections to their paper. [1]:

1. Sentences which utilized inappropriate expressions have been modified without changing the content of the sentences throughout the whole paper.

2. Sections $2.1-2.3$ have been shortened because details of the models can be found in [8-10,27].

3. Table 1 has been newly added to show decision variables in Section 3.1 clearly and make it easier for readers to understand.

4. In Sections 4.1, 4.3 and 6.1, reference numbers have been corrected because of the addition of references [27] and [31].

5. Reference [31] was added because that paper needed to be cited.

6. Copyrights of IEEE have been added to Figures 1-9. Reference [27] was newly added to explain the copyright.

The changes do not affect the scientific results. The manuscript will be updated and the original will remain online on the article web page, with a reference to this Correction.

\section{Reference}

1. Sato, M.; Fukuyama, Y.; Iizaka, T.; Matsui, T. Total Optimization of Energy Networks in a Smart City by Multi-Population Global-Best Modified Brain Storm Optimization with Migration. Algorithms 2019, 12, 15. [CrossRef]

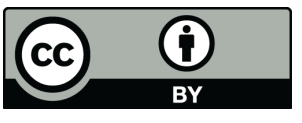

(C) 2019 by the authors. Licensee MDPI, Basel, Switzerland. This article is an open access article distributed under the terms and conditions of the Creative Commons Attribution (CC BY) license (http://creativecommons.org/licenses/by/4.0/). 